\title{
O DIREITO AO ESQUECIMENTO E A LIBERDADE DE INFORMAR NA SOCIEDADE DA INFORMAÇÃO
}

\author{
THE RIGHT TO BE FORGOTTEN AND THE FREEDOM TO INFORM IN THE \\ INFORMATION SOCIETY
}

\section{Jorge Shiguemitsu Fujita}

Doutorado em Direito Civil pela Faculdade de Direito da Universidade de São Paulo USP (2008). Professor do Programa de Mestrado em Direito da Sociedade da Informação e Professor Titular de Direito Civil do Curso de Graduação em Direito do Centro Universitário das Faculdades Metropolitanas Unidas - FMU, São Paulo. Professor da Escola Superior de Advocacia da Ordem dos Advogados do Brasil, Seção de São Paulo.

\section{Irineu Francisco Barreto Junior}

Pós-Doutorado em Sociologia pela Universidade de São Paulo - USP (2019). Doutorado em Ciências Sociais pela Pontifícia Universidade Católica de São Paulo PUC-SP (2004). Mestrado pela PUC/SP (1999). Professor do Programa de Mestrado em Direito da Sociedade da Informação e do Curso de Graduação em Direito do Centro Universitário das Faculdades Metropolitanas Unidas - FMU-SP.

\section{Resumo}

ASociedade da Informação desencadeou conflitos gerados no âmbito nacional e internacional que provocam a colisão entre dois grandes direitos: direito à liberdade de informação e direito ao esquecimento. Derivam de fatos ou acontecimentos resultantes da grande velocidade de disseminação de informações e dados, gerados a cada segundo no mundo globalizado, proporcionando não raras vezes um grande desconforto e perdas que não podem sequer ser mensuradas. A grande questão a se discutir neste artigo se refere ao critério a ser adotado para que o titular do direito ao esquecimento possa exigi-lo. Para tanto, utilizamos o método dedutivo lógico, com base em casos julgados e na doutrina. $O$ artigo conclui que, embora a liberdade de informação e a liberdade de expressão sejam erigidas ao status de direitos fundamentais, seu exercício não é absoluto. Existem limites como o princípio da dignidade da pessoa humana e os direitos da personalidade referentes à honra, à imagem, à vida privada e à intimidade das pessoas. Para solucionar o conflito entre 0 direito à liberdade de informar e o direito ao esquecimento deverá ser seguido o bom-

Rev. direitos fundam. democ., v. 25, n. 2, p. 5-27, mai./ago. 2020. 
senso e, na sua inviabilidade, deverá ser empregada a técnica da ponderação, com base no princípio da proporcionalidade ou razoabilidade para cada caso que estiver sendo apreciado.

Palavras-chave: Dados Pessoais. Direito ao Esquecimento. Liberdade de Informar. Sociedade da Informação.

\begin{abstract}
The Information Society has triggered conflicts generated at the national and international level that lead to the collision between two great rights: the right to freedom of information and the right to forgetfulness. They derive from facts or events resulting from the great speed of dissemination of information and data, generated every second in the globalized world, not infrequently causing great discomfort and losses that can not even be measured. The big question to discuss in this article refers to the criterion to be used to ensure that the holder of the right to oblivion may require it. For that, we use the logical deductive method, based on judged cases and doctrine. The paper concludes that although freedom of information and freedom of expression have fundamental rights status, their exercise is not absolute. There are limits such as the principle of the dignity of the human person and the rights of the personality concerning honor, image, private life and intimacy of people. In order to resolve the conflict between the right to freedom of information and the right to forgetfulness, common sense should be followed and, in its infeasibility, the weighting technique should be used, based on the principle of proportionality or reasonableness for each case under consideration.
\end{abstract}

Key-words: Personal Data. Right to be Forgotten.Freedom to Inform. Information Society. 


\section{CONSIDERAÇÕES INICIAIS}

A era contemporânea atravessa um novo estágio de desenvolvimento econômico, cultural, social e político, que se convencionou chamar como Sociedade da Informação, provocadora de uma série de novos desafios e paradoxos para a seara jurídica. Nesse contexto, o artigo apresenta como objetivo analisar os antagonismos entre liberdade de informação e o direito ao esquecimento de fatos ou acontecimentos, fenômeno relevante nessa era de disseminação da internet, propagação comunicativa em tempo real na qual surgem novos desafios para a defesa da privacidade e da intimidade. Com efeito, se, de um lado, todas as pessoas possuem acesso fácil e cada vez mais veloz, praticamente em tempo real, às notícias e informes sobre tudo que ocorre no nosso dia a dia, haja vista a imprensa, os buscadores, como o Google, as redes sociais, como o Facebook, ${ }^{1}$ Linkedln, Twitter, ${ }^{2}$ Skype e outros meios de comunicação, de outro lado, questiona-se se essa liberdade deveria ser submetida a limites, em certas circunstâncias, dando ensejo ao direito ao esquecimento.

O artigo adota a vertente metodológica jurídico-sociológica, que se propõe a "compreender o fenômeno jurídico no ambiente social mais amplo", ao analisar o direito como variável dependente da sociedade e trabalhar com as noções de eficiência, eficácia e efetividade das relações entre direito e sociedade (GUSTIN; DIAS, 2006, p. 56).

Jeffrey Rosen (2018)afirma, com propriedade, que o paradoxo pelo qual, em virtude de postagens de opiniões e de imagens realizadas inclusive pelo próprio usuário, pode ser mais evidenciado o que temos de pior, e não de melhor. Com efeito, assevera o autor:

Fala-se frequentemente que vivemos em uma era permissiva, com

\footnotetext{
1 No Facebook, ocorre o upload de mais de 250 milhões de fotos novas por dia, ao passo que por mais de 3 bilhões de vezes são acionados os seus botões de "curtir" ou comentários diariamente. (Alejandro Touriño. El derecho al olvido y a laintimidaden internet. Madrid: Ed. Catarata, 2014, p. 83). 2 Twitter é uma rede social e um servidor para microblogging, que permite aos usuários enviar e receber indiretas pessoais de outros contatos (em textos de até 140 caracteres, conhecidos como tweets), por meio do website do serviço, por SMS e por softwares específicos de gerenciamento (informação obtida no Wikipédia. Disponível em:<https://pt.wikipedia.org/wiki/Twitter>. Acesso em: 21 mai.2018).
} 
segundas chances infinitas. Mas a verdade é que, para a grande maioria de pessoas, o banco permanente de memória da Web significa que cada vez mais não há uma segunda chance - sem oportunidades para escapar de uma letra escarlate em seu passado digital. Agora a pior coisa que você fez é frequentemente a primeira coisa de que todo mundo venha a saber de você. ${ }^{3}$

Um dos fatos marcantes do final do século XX no Brasil, e que teve repercussão internacional, foi o caso da Escola Base, situada no bairro da Aclimação, em São Paulo, cujos proprietários e alguns funcionários foram, injustamente, acusados de abuso sexual perpetrado contra crianças na faixa etária de 4 (quatro) anos. Houve uma veiculação abusiva por parte da imprensa de fatos, que, posteriormente, foram demonstrados inexistentes. Com efeito, mesmo sem 0 término da investigação, os acusados foram detidos. A população do bairro, revoltada, depredou a escola e a residência dos acusados, que sofreram, até mesmo, a ameaça de linchamento. Transcorrido um mês dos supostos delitos, outro delegado assumiu 0 inquérito, sendo certo que as novas investigações demonstraram a existência de erros das mães de alunos, do delegado anterior e da imprensa. Todas as acusações de pedofilia eram infundadas.

Mesmo assim, diante da repercussão nociva de sua imagem, embora inocentes os seus dirigentes, a Escola Base foi fechada, diante da incredulidade dos pais de alunos, colocando-a em situação de insolvência, assim como os seus dirigentes. Ações diversas de responsabilidade civil foram movidas pelos dirigentes e professores em face da Fazenda Pública do Estado de São Paulo e de vários veículos da imprensa escrita e televisiva, porém tudo isso não bastou para devolver a confiança perdida. ${ }^{4}$ Ultrapassados mais de 20 anos dessa exposição negativa de dirigentes e professores de uma instituição de ensino à execração pública, a simples pesquisa por meio de um site buscador, como o Google, ${ }^{5}$ demonstra que um fato

\footnotetext{
${ }^{3}$ Tradução livre de: It's often said that we live in a permissive era, one with infinite second chances. But the truth is that for a great many people, the permanent memory bank of the Web increasingly means there are no second chances - no opportunities to escape a scarlet letter in your digital past. Now the worst thing you've done is often the first thing everyone knows about you. ROSEN, Jeffrey. Disponível em: <http://www.nytimes.com/2010/07/25/magazine/25privacyt2.html?pagewanted=all\&_r=1\&>. Acesso em: 21 mai.2018.

${ }^{4}$ Disponível em: <http://veja.abril.com.br/brasil/morre-icushiro-shimada-erroneamente-acusado-nocaso-da-escola-base >. Acesso em: 21 mai. 2018.

5 Consoante informação de Rex Kelly Rayner Junior e Casey G. Cegielski, o Google processa mais de 24 petabytes de dados por dia, sendo certo que cada petabyte corresponde a um quatrilhão de bytes (Introdução a sistemas de informação: apoiando e transformando negócios na era da mobilidade. Tradução de Daniel Vieira. 3. ed. Rio de Janeiro: Elsevier, 2013, p. 381). Há cerca de 8 anos atrás, o Google promovia a indexação de mais de 60 trilhões de sites. (Alejandro Touriño, op.
} 
injusto e grave ainda não é objeto de esquecimento. ${ }^{6}$ Indaga-se: não possuem os injustiçados, indevidamente acusados, o direito ao esquecimento? A lembrança de fatos pretéritos, relativos a pessoas inocentes não multiplica as suas dores morais? Afinal, não é um direito da personalidade o esquecimento? ${ }^{7}$

Outro caso emblemático é o referente ao assassinato de Aida Jacob Curi, de 18 anos de idade, no bairro de Copacabana, Rio de Janeiro. Consta que a jovem foi levada à força por dois rapazes, com a ajuda do porteiro, até o alto do edifício Rio Nobre, na Avenida Atlântica, os quais, sem sucesso, tentaram estuprá-la, promovendo, no entanto, agressões de toda ordem, até que a vítima viesse a desmaiar. Procurando simular um suicídio da vítima, um dos agressores a atirou do terraço situado no décimo segundo andar, provocando-Ihe a morte. Apesar da gravidade dos fatos, um dos rapazes e o porteiro foram condenados pelos crimes de atentado violento ao pudor e tentativa de estupro, ao passo que o outro rapaz, autor do homicídio, mas menor na época do crime, foi encaminhado apenas ao Sistema de Assistência ao Menor, após o que foi cumprir serviço militar. ${ }^{8}$ Passados 50 anos do trágico evento, a Rede Globo de Televisão, em seu programa Linha Direta Justiça, decidiu dramatizar o crime, trazendo à baila o infausto acontecimento, reabrindo as antigas feridas mal cicatrizadas de seus familiares, veiculando a vida, a morte e a pós-morte de Aida Curi.

Os irmãos Curi moveram ação de reparação de danos morais, materiais e à imagem em face da TV Globo. O Juízo de Direito da $47^{\text {a }}$ Vara Cível da Comarca do Rio de Janeiro - RJ julgou improcedentes os pedidos dos autores. Interposto recurso de apelação, o Egrégio Tribunal de Justiça do Rio de Janeiro manteve a sentença recorrida. Ainda inconformados, os irmãos de Aida Curi interpuseram

cit., p. 34.)

${ }^{6}$ Disponível em: <https://equipemidianamira.wordpress.com/2009/04/08/breve-resumo-do-casoescola-base>. Acesso em: 20.mai.2016; Disponível em: <http://jornalggn.com.br/noticia/o-casoescola-base-20-anos-depois>. Acesso em: 21 mai.2018; Disponível em: <http://www1.folha.uol.com.br/cotidiano/2014/03/1432195-imprensa-amadureceu-apos-o-caso-escolabase-aponta-debate.shtml>. Acesso em: 21.mai.2018; Disponível em: <http://www.pragmatismopolitico.com.br/2012/12/caso-escola-base-rede-globo-e-condenada-pagar-r135-milhao.html>. Acesso em 21 mai.2018; Disponível em: <http://justificando.com/2014/12/10/daserie-julgamentos-historicos-escola-base-a-condenacao-que-nao-veio-pelo-judiciario >. Acesso em 21. mai.2018; Disponível em: <http://entretenimento.r7.com/programa-do-gugu/fotos/escola-baserelembre-o-caso-que-escandalizou-o-brasil-nos-anos-90-16072015\#!/foto/1/>. Acesso em 21.mai.2018.

${ }^{7} \mathrm{Na}$ Itália, fala-se em dirittoall'oblio; na Alemanha, rechtaufvergessenwerden; na Espanha, derecho al olvido; na França, droit a l'oubli; nos Estados Unidos, right to beforgottenouright to delete.

${ }^{8}$ Disponível em: <https://pt.wikipedia.org/wiki/Caso_A\%C3\%ADda_Curi/>. Acesso em: 21 mai.2018; Disponível em: <http://canalcienciascriminais.com.br/artigo/o-direito-ao-esquecimento-na-sociedadeda-informacao-o-caso-aida-curis. Acesso em 21 mai.2018. 
recurso especial e recurso extraordinário. O recurso especial subiu para apreciação do Superior Tribunal de Justiça, por meio de agravo (AResp 15.007). Na apreciação do Recurso Especial (no 1.335.153-RJ), o Ministro Relator Luis Felipe Salomão deu o seu voto vencedor, entendendo que o direito ao esquecimento não alcançava o caso dos autos, em que havia sido revivido, 50 anos após o crime, um acontecimento que, a seu ver, havia entrado no domínio público, de tal sorte que seria "impraticável a atividade da imprensa para o desiderato de retratar o caso Aida Curi, sem Aida Curi”. Entendeu ainda o Ministro Relator ser inaplicável no caso a Súmula STJ 403 ("Independe de prova do prejuízo a indenização pela publicação não autorizada de imagem de pessoa com fins econômicos ou comerciais"). Concluiu que a imagem da falecida não foi utilizada de forma degradante ou desrespeitosa. ${ }^{9}$. Encontra-se ainda pendente de apreciação ${ }^{10}$ no Supremo Tribunal Federal o Recurso Extraordinário com Agravo (ARE 833248), cujo Relator é o Ministro Dias Toffoli, que reconheceu ab initio a repercussão geral do tema.

No plano internacional, vários casos podem ser reportados, como Melvin VS Reidnos Estados Unidos da América. Consta que Gabrielle Darley, prostituta, foi acusada de crime de homicídio em 1918, mas, submetida a julgamento, foi considerada inocente. Passado um tempo, Gabrielle, deixando a prostituição, casouse com Bernard Melvin, e com o casamento ganhou destaque na sociedade da época. Entretanto, seu período de tranquilidade foi interrompido pela produção de um filme produzido por Doroty Davenport Reid, intitulado RedKimono, que fazia reportar na película a vida pregressa de excessos de Gabrielle. A Corte de Justiça do estado da Califórnia, em 1931, ao apreciar a ação movida por seu marido, Bernard Melvin, em face de Doroty Davenport Reid, que visava à reparação pela violação à vida privada de sua esposa Gabrielle, deu-lhe ganho de causa, entendendo que uma pessoa que vive uma vida correta tem o direito à felicidade, livre de ataques a seu caráter, posição social ou reputação (DOTTI, 1980, p. 90 e 91).

Outro caso de violação ao direito ao esquecimento ocorreu com Greta

\footnotetext{
${ }^{9}$ Verifica-se que o acórdão da 4⿳亠丷a Turma do STJ, em 28.05.2013, não foi unânime $(3 \times 2)$, vencidos os votos dos Ministros Maria Isabel Gallotti e Marco Buzzi. Votaram com o Ministro Luis Felipe Salomão os Ministros Raul Araujo Filho e Antonio Carlos Ferreira.

10 Até o dia 21.05.2018, data de finalização deste artigo, não havia ocorrido o julgamento do Recurso Extraordinário com agravo pelo STF.
} 
Garbo, ${ }^{11}$ atriz sueca de grande renome no cinema norte-americano. Famosa por sua beleza, decidiu, precocemente, abandonar as câmeras de filmagem e viver no ostracismo, para que o público admirador guardasse a sua bela imagem. Após 50 (cinquenta) anos de anonimato, foi flagrada por um fotógrafo sensacionalista, um paparazzo, numa praia particular da Riviera Francesa. Sua foto correu mundo afora, recebendo comentários de toda ordem, como aquele de um jornalista que a criticava por não saber "envelhecer, mostrando suas pelancas numa praia" (COSTA JUNIOR, 2004, p. 129). Pode-se verificar e concluir, por alguns casos ilustrativos, que certamente existe uma colisão entre a liberdade de informação, de expressão e de imprensa:

os quais não podem estar submetidos a qualquer tipo de censura, e, de outro lado, os direitos da personalidade, entre eles o direito ao esquecimento, como corolário do direito à intimidade, à privacidade, à honra e à imagem, todos também com status constitucional, surgindo, assim, uma colisão entre direitos fundamentais (RAMOS FILHO, 2014, p. 53).

\section{LIBERDADE DE INFORMAÇÃO E SEUS LIMITES}

O direito à liberdade de informação consiste no direito de informar, no direito de se informar e no direito de ser informado (CANOTILHO; MOREIRA, 2007, p. 573). $\mathrm{O}$ direito de informar é fundado na liberdade de transmitir ou comunicar informes a outrem, promovendo a sua difusão sem qualquer impedimento. $O$ direito de se informar é a liberdade de obter as informações, sem que sejam feitas restrições, exceto aquelas concernentes a arquivos sigilosos próprios de serviços de inteligência. E o direito de ser informado é o que consiste no direito "a ser mantido adequadamente e verdadeiramente informado, desde logo, pelos meios de comunicação" (CANOTILHO; MOREIRA, p. 573).

O direito de informação não pode sujeitar-se a impedimentos, restrições ou discriminações. Ele não pode sofrer censura, seja ela prévia à informação originária, seja ela posterior, resultante do impedimento de sua difusão ou divulgação (CANOTILHO; MOREIRA, p. 574).

Historicamente, a Inglaterra foi a pioneira a estabelecer regras relativas à liberdade de expressão.

\footnotetext{
11 Greta Garbo, cujo nome verdadeiro era Greta LovisaGustafsson, nasceu em Estocolmo, na Suécia, em 18.09.1905 e faleceu em Nova lorque, Estados Unidos da América, em 15.04.1990.
} 
A Constituição norte-americana, com a primeira emenda aprovada em 15.12.1791, impede que o congresso adote qualquer tipo de iniciativa, visando a proibir e limitar os seus direitos fundamentais, inclusive a liberdade de expressão (FARIAS, 1996, p. 129).

A Declaração Universal dos Direitos Humanos, aprovada pela Assembleia Geral das Nações Unidas em 10.12.1948, estatui, em seu art. 19, que "Todo ser humano tem direito à liberdade de opinião e expressão; este direito inclui a liberdade de, sem interferência, ter opiniões e de procurar, receber e transmitir informações e ideias por quaisquer meios e independentemente de fronteiras".A Convenção Europeia de Salvaguarda dos Direitos do Homem e suas Liberdades Fundamentais, de 04.11.1950, fixa, em seu art. 10, item 1을

\begin{abstract}
Qualquer pessoa tem direito à liberdade de expressão. Este direito compreende a liberdade de opinião e a liberdade de receber ou de transmitir informações ou ideias sem que possa haver ingerência de quaisquer autoridades públicas e sem considerações de fronteiras. O presente artigo não impede que os Estados submetam as empresas de radiodifusão, de cinematografia ou de televisão a um regime de autorização prévia.
\end{abstract}

A nossa Constituição Federal de 1988 preconiza, no art. 5ํㅡ, em seu inciso IV, que "é livre a manifestação do pensamento, sendo vedado o anonimato"; em seu inciso $V$, que "é assegurado o direito de resposta, proporcional ao agravo, além da indenização por dano material, moral ou à imagem"; em seu inciso IX, que "é livre a expressão da atividade intelectual, artística, científica e de comunicação, independentemente de censura ou licença"; em seu inciso X, que "são invioláveis a intimidade, a vida privada, a honra e a imagem das pessoas, assegurado o direito à indenização pelo dano material ou moral decorrente de sua violação"; em seu inciso XIII, que "é livre o exercício de qualquer trabalho, ofício ou profissão, atendidas as qualificações profissionais que a lei estabelecer"; e, em seu inciso XIV, que "é assegurado a todos o acesso à informação e resguardado o sigilo da fonte, quando necessário ao exercício profissional". Ainda a nossa Carta Magna, em seu art. 220, caput, assevera que "A manifestação do pensamento, a criação, a expressão e a informação, sob qualquer forma, processo ou veículo não sofrerão qualquer restrição, observado o disposto nesta Constituição". Porém, em seguida, no $§ 1^{\circ}$ desse mesmo art. 220, o constituinte assinala que "nenhuma lei conterá dispositivo que possa constituir embaraço à plena liberdade de informação jornalística em 
qualquer veículo de comunicação social, observado o disposto no art. 5ํㅗ IV, V, X, XIII e XIV".

Assim, tanto a liberdade de informação, inclusive a jornalística, quanto a liberdade de expressão, consagradas em normas internacionais e na nossa Constituição Federal, se encontram na qualidade de:

direitos subjetivos fundamentais assegurados a todo cidadão, faculdades de manifestar de forma amplamente livre o pensamento, as ideias e opiniões através de qualquer meio de comunicação, assim como no direito de comunicar ou receber informação verdadeira, consistindo em liberdades indispensáveis ao exercício da democracia e ao desenvolvimento dos povos (RAMOS FILHO, 2014, p. 15).

No entanto, toda essa liberdade de informação e de expressão não pode ser visualizada e potencializada de maneira absoluta. Com efeito, entendemos que há limites a serem observados. O primeiro deles é o princípio fundamental da dignidade da pessoa humana, por meio do qual "o indivíduo é tratado como sujeito com valor intrínseco, posto acima de todas as coisas criadas e em patamar de igualdade de direitos com os seus semelhantes"(BRANCO, 2012, p. 346).

Também são limites os direitos da personalidade ${ }^{12}$ à honra, à imagem, à vida privada e à intimidade das pessoas. O direito à honra é aquele que se funda no:

sentimento da própria dignidade e, por via reflexa, crédito decorrente de probidade, correção, proceder reto: é o apanágio da pessoa que sabe manter a própria respeitabilidade, correspondendo, assim, à estima em que é tida quem vive de acordo com os ditames da moral (CHAVES, 1977, v. 42, p. 1).

Direito à imagem é aquele que visa a amparar "a expressão exterior sensível da individualidade humana, digna de proteção jurídica" (GAGLIANO; PAMPLONA FILHO, 2006, p. 174), consistindo na imagem-retrato, que se refere ao

\footnotetext{
12 Para Goffredo da Silva Telles Júnior(2001, p. 299), direitos da personalidade são "as autorizações dadas por meio das leis, a todas as pessoas, de defender os atributos e expressões de suas respectivas personalidades". Conforme Daisy Gogliano (1982, p. 404), direitos da personalidade são "os direitos subjetivos particulares que consistem nas prerrogativas concedidas a uma pessoa pelo sistema jurídico e asseguradas pelos meios de direito para fruir e dispor, como senhor, dos atributos essenciais da sua própria personalidade, de seus aspectos, emanações e prolongamentos, como fundamento natural da existência e liberdade, pela necessidade da preservação e resguardo da integridade física, psíquica, moral e intelectual, no seu desenvolvimento.
} 
aspecto físico da pessoa, e à imagem-atributo, que é a exteriorização da personalidade do indivíduo, considerando-o dentro da sociedade.

O direito à vida privada consiste na confidência, na amizade, na reserva, no ato humano externo, social, lícito que as pessoas queiram preservar de sua divulgação ou conhecimento de terceiros (ALONSO, 2005, p. 11-35).

O direito à intimidade é o que visa a resguardar a privacidade da pessoa em seus aspectos pessoais, familiares e negociais, tendo como ponto principal o não desejo de que determinados aspectos de sua personalidade e de sua vida cheguem ao conhecimento de terceiros, tais como confidências, dados pessoais, recordações pessoais, memórias, relações familiares, lembranças de família, sepultura, vida amorosa, ou conjugal, saúde física e mental, afeições, entretenimentos, costumes domésticos e atividades negociais, reservados pela pessoa para si e para seus familiares e, portanto, afastados da curiosidade pública (BITTAR, 2001, p. 107 e 108). Como afirmam Simão Filho e Schwartz (2016, p. 14),

na esfera da intimidade protegem-se relações intimas e não secretas, como o sigilo profissional, domiciliar e telefônico, gerando a necessidade de uma proteção mais ativa e afastando-se o acesso livre a certas informações. Já na esfera central e mais profunda, a proteção relaciona-se com segredos e opções sexuais, políticas, religiosas". É o chamado direito de estar só, o direito ao resguardo, caracterizando-se pela não exposição de elementos ou informações da esfera íntima ou reservada de seu titular (LISBOA, 2009, v. 1, p. 190).

Autores, como Moraes (2006, p. 47), entendem que o direito à intimidade se refere às relações subjetivas do trato íntimo da pessoa, enquanto o direito à vida privada abrangeria todas as demais relações inclusive aquelas de caráter objetivo. Dentro do direito à intimidade encontra-se o direito ao esquecimento.

\section{O DIREITO AO ESQUECIMENTO}

O direito ao esquecimento é, no entender de Consalter (2016, p. 204),

um direito subjetivo, de titularidade individual e não absoluto, resultante do desdobramento do direito fundamental à intimidade, mediante o qual o interessado, no exercício de sua liberdade, autonomia e determinação individual, controla se fatos pertencentes ao seu passado podem ou não ser retomados no presente, como forma de salvaguardar a sua integridade emocional, psíquica, profissional e social, além de resguardar, eficazmente, a sua vida íntima. 
É o direito de ser deixado em paz, de ficar no anonimato, que se encontra inserido no conceito de vida privada, da qual é parte (LINDON, 1974, p. 25). É o direito de eliminar, ocultar e cancelar aquelas informações ou feitos pretéritos relativos à vida das pessoas físicas e que podem condicionar o seu futuro" (SIMÓN CASTELLANO, 2012, p. 22).

O direito ao esquecimento, na visão de David Lindsay (2014, p. 292-293), oferece três finalidades: a primeira visa a impedir que o passado administrativo, judicial ou criminal de seu titular seja resgatado a todo instante; a segunda objetiva apagar os dados pessoais com fundamento na legislação que regula o direito à intimidade, onde se incluem os dados pessoais; e a terceira almeja retirar os dados pessoais online, ou restringir ou evitar o acesso a esses dados.

Para demonstrar a importância que tem a questão, em março de 2013, na VI Jornada de Direito Civil do CJF/STJ, foi aprovado o Enunciado 531, vazado nos seguintes termos: "A tutela da dignidade da pessoa humana na sociedade da informação inclui o direito ao esquecimento". Para tanto foi apresentada a justificativa de que os danos provocados pelas novas tecnologias de informação vêm-se acumulando nos dias atuais. $O$ direito ao esquecimento tem sua origem histórica no campo das condenações criminais. Surge como parcela importante do direito do ex-detento à ressocialização, não podendo ele:

ser eternamente punido, até porque isso contraria, ao menos nacionalmente, a Constituição da República Federativa do Brasil, a qual veda a aplicação de penas perpétuas (art. $\left.5^{\circ}, \mathrm{XLVII}, \mathrm{b}\right)$, de modo que os registros da condenação não devem se perpetrar além do tempo da punição (SIERRA, 2013, p. 13).

Não atribui a ninguém o direito de apagar fatos ou reescrever a própria história, mas apenas assegura a possibilidade de discutir o uso que é dado aos fatos pretéritos, mais especificamente 0 modo e a finalidade com que são lembrados.Verifica-se a amplitude do referido enunciado, não se restringindo apenas a aspectos pretéritos de pessoas que, condenadas e libertadas após o cumprimento da pena criminal, procuram se reinserir na sociedade, mas engloba, acima de tudo, a privacidade das pessoas em um mundo informatizado em que tudo o que ocorre a cada segundo é acompanhado de perto pelas demais.

Todavia, o direito ao esquecimento não é absoluto e ilimitado, porquanto 
deve ser examinado caso a caso, sobretudo quando houver um confronto com o direito à expressão e à informação ou com o direito à livre manifestação do pensamento artístico, literário e científico ou com outro direito da personalidade (LIMA, 2014, p. 97).

Efetivamente, além dos aspectos ligados à liberdade de expressão e de imprensa, pode-se arguir que esse direito poderia significar a perda da própria história, afrontando o direito à memória de toda a sociedade, provocando o desaparecimento de registros de interesse público. ${ }^{13}$

Para salvaguardar a privacidade das pessoas, em 24.10.1995 foi firmada a Diretiva 95/46/CE do Parlamento Europeu e do Conselho, assegurando a proteção das liberdades e dos direitos fundamentais das pessoas singulares, nomeadamente do direito à vida privada, no que diz respeito ao tratamento de dados pessoais. ${ }^{14}$

Com base nessa Diretiva 95/46/CE, o Tribunal de Justiça da União Europeia decidiu uma questão que teve início quando Mário Costeja González pediu ao jornal La Vanguardia que apagasse das suas edições online anúncios sobre a venda de imóveis em hasta pública, em virtude um arresto relativo a uma ação de recuperação de crédito em favor da Segurança Social, sendo que no polo passivo figurava o nome do requerente. Alegava que a pendência era antiga e que tinha sido superada havia muito tempo, inexistindo razão para a sua permanência. No entanto, o jornal se recusou a atender ao pedido, motivo pelo qual esse homem recorreu ao Google, solicitando que o anúncio não aparecesse mais como resultado de pesquisas feitas com o seu nome, porém também não obteve êxito. Em julho de 2010, a Agência Espanhola de Proteção de Dados (AEPD) determinou que o Google impedisse que o anúncio aparecesse no resultado de buscas, porém validou o direito do editor do jornal de manter o anúncio, com o fundamento de que a publicação de dados na imprensa e sua manutenção online eram legítimas. A discussão foi parar na Justiça

\footnotetext{
${ }^{13}$ Rodrigo Janot Monteiro de Barros, Procurador-Geral da República, questiona se a proposta de reconhecimento do direito a esquecimento como decorrência do princípio da dignidade humana, em vez de contribuir para consistência do sistema jurídico e para a força normativa da Constituição, não estaria a concretizar interesses particularistas e por limitar de forma injustificada importantíssimos direitos fundamentais assegurados a todos, como as liberdades de expressão e comunicação (Parecer no 156.104/2016 - PGR-RJMB, exarado em 11.07.2016, opinando pelo não provimento do Recurso Extraordinário com agravo 833.248/RJ, em que figuram, como Agravantes, Nelson Curi, Roberto Curi, Waldir Cury e Maurício Curi (irmãos de Aida Curi) e, como Agravada, Globo Comunicação e Participações S/A, sendo Relator o Ministro Dias Toffoli). Esse recurso ainda não foi julgado até esta data (21.05.2018).

${ }^{14}$ Disponível em: <http://ec.europa.eu/justice/policies/privacy/docs/95-46-ce/dir1995-46_part1_pt.pdf.> Acesso em: 21 mai.2018.
} 
e, antes de decidir, o tribunal espanhol pediu uma orientação à corte da União Europeia. Em 13.05.2014, o Tribunal de Justiça da União Europeia, no processo C131-12, decidiu que o Google era responsável pelos links que exibia como resultado de buscas e poderia ser obrigado a apagar a ligação para determinados sites, caso ficasse comprovada qualquer violação a direitos individuais. Em outras palavras, essa decisão significou que, sempre que alguém se incomodasse com determinada página na web, poderia pedir diretamente aos provedores e administradores de sites de busca, como o Google, para não a relacionarem mais a uma pesquisa com o seu nome. O Tribunal de Justiça da União Europeia entendeu que, ainda que o site que publicou originalmente determinada informação não a apagasse, a Justiça poderia obrigar que a página fosse suprimida do resultado de buscas, desde que o pedido fosse devidamente justificado. $O$ prejudicado deveria formular 0 pedido primeiramente ao Google e, em caso de negativa, recorrer à Justiça (PINHEIRO, 2018).

Nos Estados Unidos da América, especificamente no estado da Califórnia, foi editada a Lei SB-568, de 23.09.2013, a qual garante aos menores de idade o direito de apagar informações embaraçosas que se encontrem em sites da internet, sobretudo das redes sociais, como o Facebook, Twitter e a Tumblr. ${ }^{15}$ Veda, ainda, de maneira impositiva, a publicidade de produtos como armas, álcool, tabaco e produtos de dieta. Objetiva, enfim, proteger um grupo de pessoas vulneráveis ao denominado cyberbullying (PIMENTEL; CARDOSO 2015, p. 53).

$\mathrm{Na}$ França, podemos nos valer de sua experiência legislativa, que, em sua Lei de Imprensa, ${ }^{16}$ proíbe, no art. 35 , a prova da verdade de imputação difamatória relativa a fatos da vida privada da pessoa, ou a fatos que remontem há mais de dez anos, ou a um fato que consista em uma infração anistiada ou prescrita. Há ainda na França a Lei 78-17, de 06.01.1978, que estabelece, em seu art. 10, ${ }^{17}$ que a informática não deverá atentar contra a identidade humana nem contra os direitos do

\footnotetext{
${ }^{15}$ Tumblr é uma plataforma de blogging, que permite aos usuários publicarem textos, imagens, vídeos, links, citações, áudio e diálogos. A maioria dos posts feitos no Tumblr é composta de textos curtos, mas a plataforma não chega a ser um sistema de microblog, estando em uma categoria intermediária entre os blogs de formato convencional Wordpressou Blogger e o microblog Twitter (Informação obtida no wikipédia. Disponível em: <https://pt.wikipedia.org/wiki/Tumblr>. Acesso em: 21.mai.2018).

${ }^{16}$ Loisurla Presse, de 29 de julho de 1881, atualizada pela Lei n. 98-468, de 17.06 .1998 e pela Ordenança n. 2000-916, de 19.09.2000.

${ }^{17} \mathrm{Loi}$ 78-17. Article 1er. L'informatiquedoitêtreauservice de chaquecitoyen. Son développementdoits'opérerdans le cadre de la coopérationinternationale. Elle ne doitporteratteinteni à l'identitéhumaine, niauxdroits de l'homme, ni à lavieprivée, niauxlibertésindividuelles ou publiques.
} 
homem, sua vida privada, suas liberdades individuais e públicas. $O$ art. 6ํ18 preconiza que os dados pessoais devem ser coletados e tratados de maneira leal e lícita, para finalidades determinadas, explícitas e legítimas e que não serão posteriormente tratados de modo incompatível com essas finalidades. Ressalta que o processamento posterior de dados pessoais para fins estatísticos ou de pesquisa científica ou histórica é considerado compatível com o objetivo inicial da coleta de dados. $\mathrm{O}$ art. $7^{019}$ assevera que o processamento de dados pessoais deve receber 0 prévio consentimento da pessoa titular.

Ainda na França foram elaborados dois acordos ou cartas: uma carta a respeito do direito ao esquecimento em publicidade segmentada sobre dados pessoais coletados sem o conhecimento do internauta (Chartedudroit à l'oublinumériquedanslapublicitéciblée), firmada em 30.09.2010; outra carta é referente ao direito ao esquecimento em sites colaborativos e motores de busca de dados pessoais publicados intencionalmente pelos internautas (Chartedudroit à l'oublidansles sites collaboratifs et lesmoteurs de recherche), celebrada em 13.10.2010. As referidas cartas decorreram de uma iniciativa do governo francês com a colaboração da iniciativa privada, ${ }^{20}$ visando à proteção da vida íntima dos

\begin{abstract}
${ }^{18}$ Article 6. Untraitement ne peutporter que surdesdonnées à caractèrepersonnelquisatisfontauxconditionssuivantes: 1. Lesdonnéessontcollectées et traitées de manièreloyale et licite; 2. Ellessontcollectéespourdesfinalitésdéterminées, explicites et légitimes et ne sontpastraitéesultérieurement de manièreincompatibleaveccesfinalités. Toutefois, untraitementultérieur de données à des fins statistiques ou à des fins de recherchescientifique ou historique est considérécommecompatibleaveclesfinalitésinitiales de lacollectedesdonnées, s'il est réalisédanslerespectdesprincipes et desprocéduresprévusauprésentchapitre, auchapitre IV et à lasection 1 duchapitre $V$ ainsiqu'auxchapitres IX et $X$ et s'il n'est pasutilisépourprendredesdécisions à l'égarddespersonnesconcernées; 3. Ellessontadéquates, pertinenteset non excessives au regard des finalités pour lesquellesellessontcollectées et de leurstraitementsultérieurs; 4. Ellessontexactes, complètes et, sinécessaire, mises à jour; les mesuresappropriéesdoiventêtreprises pour que les donnéesinexactesouincomplètes au regard des finalités pour lesquellesellessontcollectéesoutraitéessoienteffacéesourectifiées; 5. Ellessontconservées sous uneformepermettantlidentification des personnesconcernées pendant unedurée qui n'excède pas la duréenécessaire aux finalités pour lesquellesellessontcollectéesettraitées.

${ }^{19}$ Article 7 Un traitement de données à caractère personnel doitavoirreçu le consentement de la personneconcernéeousatisfaire à l'une des conditions suivantes: 1. Le respect d'une obligation légaleincombant au responsable du traitement; 2. La sauvegarde de la vie de la personneconcernée; 3. L'exécutiond'une mission de service public dontestinvesti le responsableou le destinataire du traitement; 4. L'exécution, soit d'un contratauquel la personneconcernéeestpartie, soit de mesuresprécontractuellesprises à la demande de celle-ci; 5 . La réalisation de l'intérêtlégitimepoursuivi par leresponsabledutraitement ou par ledestinataire, sousréserve de ne pasméconnaîtrel'intérêt ou lesdroits et libertésfondamentaux de lapersonneconcernée.
\end{abstract}

${ }^{20} \mathrm{ACTION}$ INNOCENCE; BENCHMARK GROUP; Cabinet Alain Bensoussan; CNAFC Confédérationnationale des associations familialescatholiques; E-ENFANCE; MICROSOFT FRANCE; PAGESJAUNES; SKYROCK.COM; TROMBI.COM; UNAF Union nationale des associations familiales; VIADEO; AUFEMININ.COM; REZOTOUR. Lamentavelmente negaram-se a assinar essa Carta as 
usuários da internet, assim como a melhoria das condições de transparência do uso destes e o gerenciamento de seus dados pelos interessados (CONSALTER, 2016, p. 269).

Essas cartas francesas demonstram que a proteção da privacidade não pode ser alcançada tão somente pelos corpos judicial e administrativo, mas, sobretudo, pela atuação responsável dos cidadãos implicados no caso de poder ser objeto de intensos processos em curso de recolhimento de dados, ou no caso de conhecer o fenômeno e de exercitar os direitos legais que foram confiados por lei nas diversas etapas do processo de coleta e tratamento de dados pessoais (CONSALTER, 2016, p. 269). Sem dúvida, é elogiável a iniciativa francesa.

No direito brasileiro, temos a Lei n. 12.965, de 23.04.2014, que estabelece o marco civil da internet, fixando princípios, garantias, direitos e deveres para o seu uso no Brasil. Embora estabeleça, em seu art. 3ํ, inciso I, a garantia da liberdade de expressão, comunicação e manifestação de pensamento, essa norma jurídica também assegura, no art. 3ำ, incisos II e III, a proteção da privacidade e a preservação dos dados pessoais na forma da lei; e no art. 7으, inciso I, a inviolabilidade da intimidade e da vida privada, sua proteção e indenização pelo dano material ou moral decorrente de sua violação. Ainda no art. $7^{\circ}$, desta feita no inciso X, estabelece a Lei n. 12.965, de 23.04.2014, a nosso ver, de maneira explícita, o direito ao esquecimento, ao assegurar ao usuário da internet o direito de exclusão definitiva dos dados pessoais que tiver fornecido à determinada aplicação de internet, a seu requerimento, ao término da relação entre as partes, ressalvadas as hipóteses de guarda obrigatória de registros previstas na lei. Observe-se, no entanto, que esse direito de esquecimento não é absoluto, na medida em que a lei, em seu art. 13, caput, determina que os registros de conexão à internet deverão ser mantidos pelo administrador de sistema autônomo, sob sigilo, em ambiente controlado e de segurança, pelo lapso temporal de 1 (um) ano. Já os registros de acesso a aplicações de internet deverão ser mantidos pelo provedor de aplicações de internet, sob sigilo, em ambiente controlado e de segurança, pelo prazo de 6 (seis) meses (art. 15, caput). A objeção que fazemos é em relação aos prazos acima assinalados, os quais poderiam ser diminuídos pela metade.

No campo da responsabilidade civil por danos resultantes de conteúdo

empresas Google e Facebook. 
gerado por terceiros, a Lei n. 12.935/2014 faz uma distinção entre o provedor de conexão à internet e o provedor de aplicações de internet. Com efeito, quanto ao provedor de conexão à internet, fica bem claro que não será responsabilizado civilmente por danos decorrentes de conteúdo gerado por terceiros (art. 18). Todavia, quanto ao provedor de aplicações de internet, este somente poderá ser responsabilizado civilmente, por danos decorrentes de conteúdo gerado por terceiros se, após ordem judicial específica, não tomar as providências para, no âmbito e nos limites técnicos do seu serviço e dentro do prazo assinalado, tornar indisponível o conteúdo apontado como infringente (art. 19). Deste modo, apenas serão responsabilizados os provedores de aplicações de internet que continuarem a disponibilizar os conteúdos objetados pela decisão judicial (PIMENTEL; CARDOSO, 2015, p. 57).

Para regulamentar essa lei, foi editado o Decreto n. 8.771, de 11.05.2016, que estabelece que, tendo em vista o disposto nos incisos VII a X do caput do art. $7^{\circ}$ da Lei n. 12.965/2014, os provedores de conexão e aplicações devem reter a menor quantidade possível de dados pessoais, comunicações privadas e registros de conexão e acesso a aplicações, os quais deverão ser excluídos tão logo atingida a finalidade de seu uso ou se encerrado o prazo determinado por obrigação legal.

Fazendo uma comparação entre a Lei n. 12.965, de 23.04.2014, e a Diretiva 95/46/CE do Parlamento Europeu e do seu Conselho, datada de 24.10.1995, concluímos que a norma jurídica brasileira, diferentemente da diretiva europeia, se apresenta como um "direito subjetivo de natureza potestativa, na medida em que o seu exercício não depende da vontade do sujeito passivo" (PIMENTEL; CARDOSO, 2015, p. 56), sendo certo que a "relação jurídica mantida entre o usuário e o provedor de aplicações de internet pode ser rescindida imotivadamente a qualquer tempo pelo usuário" (PIMENTEL; CARDOSO, 2015, p. 56).

\section{COMO SOLUCIONAR O CONFLITO ENTRE O DIREITO À LIBERDADE DE INFORMAR E O DIREITO AO ESQUECIMENTO}

Para o cenário nacional, entendemos que o conflito entre o direito à liberdade de informar (CF, art. 5ํㅡ, IV, V, IX e XIV) e o direito ao esquecimento contido dentro do direito à intimidade (CF, art. $\left.5^{\circ}, \mathrm{X}\right)$ deverá ser solucionado caso a caso, não de maneira aleatória, mas seguindo o bom-senso, objetivando a 
conciliação dos direitos conflitantes. Na impossibilidade, acreditamos que o melhor critério é o da ponderação, que é "uma técnica de decisão empregada para solucionar conflitos normativos que envolvam valores ou opções políticas, em relação aos quais as técnicas tradicionais de hermenêutica não se mostram suficientes" (MARMELSTEIN, 2013, p. 378). Barroso (2012, p. 358-359) visualiza a técnica da ponderação em três etapas. Na primeira, deverá o hermeneuta observar quais são as normas jurídicas de importância para solucionar o caso. Recomenda que, nessa etapa, os diversos fundamentos normativos sejam agrupados em virtude da solução que estejam sugerindo. Na segunda etapa, o hermeneuta deverá promover um exame dos fatos, das circunstâncias concretas do caso e de sua interação com os elementos normativos.

E na terceira (e última) etapa, os diferentes grupos de normas e a repercussão dos fatos do caso concreto deverão ser levados a exame de maneira conjunta, de modo a apurar os pesos a serem atribuídos aos diversos elementos em disputa e, portanto, o grupo de normas a preponderar no caso (BARROSO, 2012, p. 358-359). Mas prossegue Barroso (2012, p. 358-359) que "é preciso ainda decidir quão intensamente esse grupo de normas - e a solução por ele indicada - deve prevalecer em detrimento dos demais, isto é: sendo possível graduar a intensidade da solução escolhida, cabe ainda decidir qual deve ser o grau apropriado em que a solução deve ser aplicada. Todo esse processo intelectual tem como fio condutor o princípio instrumental daproporcionalidadeourazoabilidade" (BARROSO, 2012, p. 358-359), a qual consiste em uma "verificação da relação custo-benefício da medida, isto é, da ponderação entre os danos causados e os resultados a serem obtidos" (BARROSO, 2006, p. 286).

Utilizando-se o critério da ponderação para o conflito entre o direito ao esquecimento e o direito à liberdade de informar, deve-se defluir, pelo exame do caso em concreto, se existiu interesse público, histórico ou à memória de um povo ou nação, e se o direito a ser esquecido esbarrou na liberdade de informação ou expressão. Nessa hipótese não há que se falar em direito a esquecimento (CONSALTER, 2016, p. 395).

Assim, para que se preserve o direito ao esquecimento, é necessário que inexista o interesse público. Ainda, há que se acrescentar o incômodo, o sofrimento e a angústia à pessoa, com danos à sua vida íntima, a sua perpetuação na internet por meio dos vários sites de busca de conteúdo, sendo certo que os informes, dados 
pessoais e imagens referentes à intimidade de uma pessoa deveriam permanecer somente por um determinado período, ficando sua manutenção virtual dependente de autorização por escrito de seu titular, sem o que seriam retirados de todos os buscadores (CONSALTER, 2016, p. 396).

Finalizando, ainda que alguns acontecimentos tenham chamado a atenção do interesse público, é possível realizar a desindexação dos dados pessoais e das imagens ligadas à privacidade de uma determinada pessoa, mesmo para programas, peças teatrais ou filmes que tenham se baseado nesses eventos, preservando-se a dignidade da pessoa humana e evitando, deste modo, a perpetuação de lembranças que ficaram no passado.

\section{CONSIDERAÇÕES FINAIS}

Conforme assinalado preliminarmente, o artigo apresentou como objetivo analisara colisão entre os princípios da liberdade de expressão versus proteção da privacidade e da intimidade, frente aos desafios impostos pela nova era denominada Sociedade da Informação. Focou no direito ao esquecimento como possibilidade de preservar princípios jurídicos basilares, estremecidos pela nova era digital.

Conclui que, embora a liberdade de informação e a liberdade de expressão sejam erigidas ao status de direitos fundamentais, seu exercício não é absoluto, na medida em que existem limites como o princípio da dignidade da pessoa humana e os direitos da personalidade referentes à honra, à imagem, à vida privada e à intimidade das pessoas. Em particular, dentro do direito à intimidade está o direito ao esquecimento, o qual consiste no direito de alguém ser deixado em paz, de ficar no anonimato, o direito de se encontrar com o seu eu interior. Todavia, o direito ao esquecimento também não é absoluto e ilimitado, sobretudo quando colocado em colidência com outros direitos fundamentais.

Ganha relevância esse direito a ponto de ser discutido em nível nacional e internacional, tendo em vista o surgimento de centenas de casos referentes a esse embate envolvendo o direito de informar versus o direito de esquecer.Sempre importante lembrar que o Direito é fato social e que o fenômeno jurídico é resultado da realidade social, emanando desta por meio dos instrumentos e instituições destinados a formular o Direito. A teoria clássica ensina que alterações na estrutura social, nos pactos estabelecidos para sua sustentação e existência, 
assim como movimentos de mudança cultural, política e econômica, provocam transformações também nas estruturas jurídicas. Desse modo, faz-se necessário refletir sobre as relações existentes entre as dinâmicas e processos sociais e as manifestações das instituições de Direito e o aparato tecnológico da Sociedade da Informação, novo paradigma tecnológico, social, cultural e comportamental estabelecido como marco analítico para qualificar o modelo de sociedade, resultado das transformações verificadas nas décadas recentes, provocadas pela formatação de um cenário mundial interligado pela tecnologia e influenciado por essa transformação nas suas mais diferentes nuances.

No âmbito internacional, especificamente na Comunidade Europeia, foi editada a Diretiva 95/46/CE do Parlamento Europeu e do Conselho. Na Califórnia, Estados Unidos da América, foi elaborada a Lei SB-568, de 23.09.2013, assegurando aos menores o direito de apagar as informações que lhes trouxessem embaraços no ambiente virtual da internet e proibindo a publicidade de determinados produtos considerados nocivos à sua saúde. $\mathrm{Na}$ França, depreendemos uma legislação que objetiva a proteção da identidade humana e de sua privacidade, condicionando o processamento de dados ao prévio consentimento de seu titular. Mesmo assim, decidiram os franceses, em 2010, elaborar uma carta/acordo sobre o direito ao esquecimento em publicidade segmentada sobre dados pessoais coletados sem o conhecimento do internauta, assim como uma carta/acordo sobre o direito ao esquecimento em sites colaborativos e motores de busca de dados pessoais publicados voluntariamente pelos internautas. O objetivo delas era a proteção da vida íntima dos internautas.

No Brasil, em 2014, foi promulgada a Lei 12.965/2014, que regula o marco civil da internet, com a proteção da privacidade e dos dados pessoais, assim como da inviolabilidade da intimidade e da vida privada. Na hipótese de sua violação, prevê que serão responsabilizados os provedores de aplicações de internet que continuarem a disponibilizar os conteúdos contrapostos pela sentença judicial. Aguarda-se para 2020 o término da vacatio legis da Lei Geral de Proteção de Dadose, considerando-se que nas últimas duas décadas cresceu de forma exponencial a captação de dados pessoais, no Brasil e no mundo, espera-se que essa nova legislação ofereça instrumentos mais efetivos voltados à proteção jurídica da privacidade, particularmente aqueles voltados à formulação de mecanismos para proteção deregistros dos usuários de tecnologias e aplicações 
dainternet.

Para a solução do conflito entre o direito à liberdade de informar e o direito ao esquecimento, deverá ser seguido o bom-senso e, na sua inviabilidade, deverá ser empregada a técnica da ponderação, com base no princípio da proporcionalidade ou razoabilidade para cada caso que estiver sendo apreciado.

\section{REFERÊNCIAS}

ALONSO, Félix Ruiz. Pessoa, intimidade e o direito à privacidade. In: SIMÃO FILHO, Adalberto; MARTINS, Ives Gandra da Silva; PEREIRA JUNIOR, Antônio Jorge (Coordenadores). Direito à privacidade. São Paulo: Centro de Extensão 
Universitária: Ideias e Letras, 2005.

BARROSO, Luís Roberto. Curso de Direito Constitucional Contemporâneo: os conceitos fundamentais e a construção do novo modelo. 3. ed. São Paulo: Saraiva, 2012.

Interpretação e aplicação da constituição. 6. ed. Revista, atualizada e ampliada. São Paulo: Saraiva, 2006.

BITTAR, Carlos Alberto. Os direitos da personalidade. 5. ed. Atualizada e aumentada por Eduardo Carlos Bianca Bittar. Rio de Janeiro: Forense Universitária, 2001.

BRANCO, Paulo Gustavo Gonet; COELHO, Inocêncio Mártires; MENDES, Gilmar Ferreira. Curso de Direito Constitucional. 6. ed. São Paulo: Saraiva, 2012.

CANOTILHO, J. J. Gomes. MOREIRA, Vital. Constituição da República

Portuguesa Anotada. 4. ed. Coimbra, PT: Coimbra Editora, 1. ed. São Paulo:

Editora Revista dos Tribunais, 2007.

CHAVES, Antônio. Honra. Verbete na Enciclopédia Saraiva do Direito. Coordenação:

CONSALTER, Zilda Mara. Para além do rio Lete: o direito ao esquecimento como aporte técnico para a proteção efetiva da intimidade na era virtual.Tese de Doutorado apresentada ao Departamento de Direito Civil da Faculdade de Direito da Universidade de São Paulo. São Paulo, 2016.

COSTA JÚNIOR, Paulo José da. O direito de estar só: tutela penal da intimidade. 3. ed. São Paulo: Siciliano Jurídico, 2004.

DOTTI, René Ariel. Proteção da vida privada e liberdade de informação. São Paulo: Editora Revista dos Tribunais, 1980.

FARIAS, Edilson Pereira de. Colisão de direitos: a honra, a intimidade, a vida privada e a imagem versus a liberdade de expressão e informação. Porto Alegre: Ed. Sergio Antonio Fabris, 1996.

GAGLIANO, Pablo Stolze; PAMPLONA FILHO, Rodolfo. Novo Curso de Direito Civil - Parte Geral.8. ed.São Paulo: Saraiva, 2006.

GOGLIANO, Daisy. Dissertação de Mestrado apresentada no Curso de PósGraduação Stricto Sensu da Faculdade de Direito da Universidade de São Paulo, São Paulo, 1982.

GUSTIN, Miracy B.S.; DIAS, Maria Teresa Fonseca. (Re)pensando a pesquisa jurídica. 2.ed. ver., ampl. eatual. Belo Horizonte: Del Rey, 2006.

LIMA, Cíntia Rosa Pereira de. Direito ao esquecimento e internet: o fundamento legal no direito comunitário europeu, no direito italiano e no direito brasileiro.Revista dos Tribunais, São Paulo, ano 103, v. 946, p. 77-109, agosto/2014. 
LINDON, Raymond. Le droits de lapersonnalité. Paris: Dalloz, 1974.

LINDSAY, David. The right to be forgotten in European data protection Law. In

LISBOA, Roberto Senise. Manual de Direito Civil - Teoria Geral do Direito Civil.5. ed. São Paulo: Saraiva, 2009, v. 1.

MARMELSTEIN, George. Curso de Direitos Fundamentais.4. ed. São Paulo: Atlas, 2013

MORAES, Alexandre de. Direito Constitucional. 19. Ed. São Paulo: Atlas, 2006.

PIMENTEL, Alexandre Freire; CARDOSO, Mateus Queiroz.A regulamentação do direito ao esquecimento na lei do marco civil da Internet e a problemática da responsabilidade civil dos provedores.In: Revista da AJURIS, v. 42, nํ137, março 2015.

A regulamentação do direito ao esquecimento na lei do marco civil da Internet e a problemática da responsabilidade civil dos provedores. Disponível em: http://www.ajuris.org.br/OJS2/index.php/REVAJURIS/article/view/376/310. Acesso em: 21 mai.2018.

PINHEIRO, Patrícia Peck. Direito Digital. 6. ed. São Paulo: Saraiva, 2016.

RAMOS FILHO, Evilásio Almeida. Direito ao esquecimento versus liberdade de informação e de expressão: a tutela de um direito constitucional da personalidade em face da sociedade da informação. Monografia apresentada ao Curso de Especialização em Direito Constitucional da Escola Superior da Magistratura do Estado do Ceará - ESMEC. Fortaleza (CE), 2014.

RAYNER JUNIOR, Rex Kelly. CEGIELSKI, Casey G. Introdução a sistemas de informação: apoiando e transformando negócios na era da mobilidade.

Tradução de Daniel Vieira. 3. ed. Rio de Janeiro: Elsevier, 2013.

ROSEN, Jeffrey. Disponível em:

http://www.nytimes.com/2010/07/25/magazine/25privacy-

t2.html?pagewanted=all\&_r=1\&. Acesso em: 21 mai.2018.

SIERRA, Joana de Souza. Um estudo de caso: o direito ao esquecimento contra a liberdade de imprensa.Monografia apresentada como Trabalho de conclusão de curso de graduação em direito. Florianópolis: Universidade Federal de Santa Catarina - UFSC, 2013.

SIMÃO FILHO, Adalberto. SCHWARTZ, Germano André Doederlein. Big data, Big problema! Paradoxo entre o direito à privacidade e o crescimento sustentável. In: IV Encontro Internacional do CONPEDI/OÑATI, Teorias Sociais e Contemporâneas do Direito. Organizadores: Diógenes Vicente Hassan Ribeiro e Germano André Doederlein Schwartz. Florianópolis: CONPEDI, 2016.

SIMÓN CASTELLANO, Pere. El régimen constitucional delderecho al olvido digital.Valencia (España): TirantLoBlanch, 2012. 
TELLES JÚNIOR, Goffredo. Iniciação na Ciência do Direito. São Paulo: Saraiva, 2001.

TOURIÑO, Alejandro. El derecho al olvido y a laintimidaden internet. Madrid: Ed. Catarata, 2014.

\section{DOCUMENTOS ELETRÔNICOS}

Breve resumo do Caso Escola Base. Disponível em:

<https://equipemidianamira.wordpress.com/2009/04/08/breve-resumo-do-casoescola-base/>. Acesso em: 21 mai.2018.

Caso Escola Base: Rede Globo é condenada a pagar indenização. Disponível em: <http://www.pragmatismopolitico.com.br/2012/12/caso-escola-base-rede-globoe-condenada-pagar-r-135-milhao.html/>. Acesso em: 21 mai.2018.

Diretiva 95/46/CE do Parlamento Europeu e do Conselho. Disponível em: <http://ec.europa.eu/justice/policies/privacy/docs/95-46-ce/dir1995-46_part1_pt.pdf>. Acesso em: 21 mai. 2018.

Escola Base: a condenação que não veio pelo Judiciário. Disponível em: $<$ http://justificando.com/2014/12/10/da-serie-julgamentos-historicos-escola-base-acondenacao-que-nao-veio-pelo-judiciario >.Acesso em: 21 mai.2018.

Escola Base: relembre o caso que escandalizou o Brasil nos anos $\mathbf{9 0 .}$

Disponível em: <http://entretenimento.r7.com/programa-do-gugu/fotos/escola-baserelembre-o-caso-que-escandalizou-o-brasil-nos-anos-90-16072015\#!/foto/1/>.Acesso em: 21 mai. 2018.

Imprensa Amadureceu após o Caso Escola Base. Disponível em: <http://www1.folha.uol.com.br/cotidiano/2014/03/1432195-imprensa-amadureceuapos-o-caso-escola-base-aponta-debate.shtml>. Acesso em: 21.mai.2018.

NASSIF, Luiz. 0 caso Escola Base 20 anos depois. Disponível em: <http://jornalggn.com.br/noticia/o-caso-escola-base-20-anos-depois/>. Acesso em: 21 mai. 2018.

REVISTA VEJA.Escola base: relembre o caso que escandalizou o Brasil nos anos 90. Disponível em: <http://veja.abril.com.br/brasil/morre-icushiro-shimadaerroneamente-acusado-no-caso-da-escola-base>. Acesso em: 21.mai.2018.

SUPREMO TRIBUNAL FEDERAL. Recurso Extraordinário com Agravo (ARE 833248). Disponível em: <http://canalcienciascriminais.com.br/artigo/o-direito-aoesquecimento-na-sociedade-da-informacao-o-caso-aida-curi/>. Acesso em: 21 mai. 2018. 